\author{
Goonewardene $\mathrm{SS}^{1 *}$ and Ready $\mathrm{A}^{2}$ \\ ${ }^{1}$ Guys and St Thomas Hospitals, London, UK \\ ${ }^{2}$ University Hospital Birmingham, UK \\ Dates: Received: 04 December, 2015; Accepted: \\ 25 January, 2016; Published: 01 February, 2016 \\ *Corresponding author: Goonewardene SS, Guys \\ and St Thomas Hospitals, London, UK, E-mail: \\ ssg7727@yahoo.co.uk \\ www.peertechz.com \\ ISSN: 2455-5495
}

Keywords: Parathyroidectomy; Calcium

supplementation; Preloading

\section{Research Article \\ Parathyroidectomies: Pre and Post Op Usage of Calcium Supplementation and Effect on Calcium Levels}

\section{Introduction}

In the U.K, the incidence of chronic renal failure (CRF) is 600 per million per population, per year and the incidence of ESRF is 200 per million per year [1].

Secondary hypoparathyroidism is the result of physiologic/ pathophysiologic parathyroid response to hypocalcaemia [2]. In most cases this is caused by chronic renal failure due to decreased dihydroxy vitamin $\mathrm{D}_{3}$. This secondary hyperparathyroidism leads to increased osteoclastic activity, cystic formation and bone marrow fibrosis, as well as impaired mineralization of osteoid (osteomalacia) and adynamic bone disease. Bone changes in patients with chronic renal failrue vary. At one end is pure osteotis fibrosis (excessive bone resorption) and at the other is osteomalacic bone disease [3]. Osteomalacia is recognized histologically by excessive amounts of osteoid/ sclerosis. Histologically, the sclerosed bone exhibits an increase in the thickness of the trabeculae, and roentgenographically, there is a coarsening of the trabecular pattern with increased opacity of the mineralized tissues [3].

Secondary hyperparathyroidism may be asymptomatic, or symptomatic, including overt bone disease, renal stones, nonspecific GI, cardiovascular and neurological manifestations [4]. Indications for surgery in hyperparathyroidism remain controversial but can include symptomatic disease, renal stones, impaired renal function, bone involvement or marked reduction in bone density. The standard approach is bilateral neck exploration, with identification and excision of all four parathyroid glands [4]. Post-operative care focuses on monitoring patients for complications e.g. symptomatic hypocalcaemia, and other rarer complications being haemorrhage, recurrent laryngeal nerve palsies and vocal cord paralysis [2]. Due to hypocalcaemia post op, pre-op calcium loading should occur. However not much research has been conducted into this area.

\section{Methods}

We retrospectively reviewed patients with hyperparathyroidism secondary to renal failure admitted to a single centre, single surgeon, for parathyroidectomies. The following were determined: calcium preloading (type and dose) in secondary hyperparathyroidism, average calcium level on admission and post op, for preloaded and non-loaded secondary hyperparathyroid cases. This was also determined for primary hyperparathyroidism and renal transplant cases to see if there was a significant difference. Notes were also reviewed for oral calcium supplementation or IV calcium supplemenyation (type and average dose), for preloaded/ non preloaded cases, primary cases and new transplants. Length of stay was also reviewed. Statistical differences will be calculated. Results will be analysed using percentages. 


\section{Results}

$33 \%$ (5 out of 15 patients) admitted for parathyroidectomy had been preloaded with calcium (Table 1). 26.4\% (4 patients) were admitted on $4 \mathrm{mcg}$ once daily of alfacalcidol, $6.6 \%$ (1 patient) was admitted on $1 \mathrm{mcg}$ alfacalcidol twice daily, with 1 tablet calcichew TDS. As expected neither primary cases, nor new transplants had been preloaded. These results are significantly different therefore could not have occurred due to chance.

The non-loaded secondary hyperparathyroidism cases have the highest calcium levels pre-op, followed by new transplant cases and primary cases, with preloaded secondary hyperparathyroidism cases coming in last. These results are very significantly different $(\mathrm{p}<0.001)$ Table 2. Highest average calcium levels post op are shown by new transplant cases, followed by primary and preloaded secondary cases, Table 3. The non-loaded cases demonstrate the lowest levels. However, these results are not significantly different.

All pre and non-loaded secondary hyperparathyroidism patients required oral calcium supplementation post op, whilst $66 \%$ (2cases) of new transplants and only $11.7 \%$ (2cases) of primary hyperparathyroidism required calcium supplementation post op (Table 4).

Tables 3,5, Higher doses of all medications except calcium acetate were required for non-preloaded cases compared to preloaded cases. Primary and new transplant cases required a far lower level of supplementation, compared to secondary cases. The doses involved with each category were not significantly different, however, the number of cases to which alfacalcidol, calcichew $(\mathrm{p}<0.001)$, and calcium acetate $(p>0.05,<0.01)$ were given in each category are significantly different.

All pre and non-loaded secondary hyperparathyroidism patients required oral calcium supplementation post op, whilst $66 \%$ ( 2 cases) of new transplants and only $11.7 \%$ (2cases) of primary hyperparathyroidism required calcium supplementation post op.

Non -preloaded cases are admitted for the longest period of time, followed by non-preloaded cases, then primaries and new transplants. These results are significantly different.

Table 1: showing numbers of secondary/ primary hyperparathyroid cases and new transplants having calcium preloading on admission.

\begin{tabular}{|l|l|l|}
\hline $\mathbf{P}<\mathbf{0 . 0 5}, \mathbf{> 0 . 0 1}, \mathbf{2}$ d.f & Preloaded & Non-preloaded \\
\hline Secondary hyperparathyroidism & 5 & 10 \\
\hline Primary hyperparathyroidism & 0 & 17 \\
\hline New transplants & 0 & 3 \\
\hline
\end{tabular}

Table 2: Average calcium level on admission for.

Preloaded secondary hyperparathyroid cases ( $\mathrm{mmol}$ )

2.47

Non loaded secondary hyperparathyroid cases (mmol)

2.73

Primary hyperparathyroid cases (mmol)

2.61

New Transplants (mmol)

2.65

$(p<0.001,2 d . f)$

Table 3: Average calcium level post op for.

\begin{tabular}{|l|l|}
\hline Preloaded secondary hyperparathyroid cases (mmol) & 2.22 \\
\hline Non loaded secondary hyperparathyroid cases (mmol) & 2.12 \\
\hline Primary hyperparathyroid cases (mmol) & 2.23 \\
\hline New Transplants (mmol) & 2.36 \\
\hline$(p>0.10,2$ d.f.) & \\
\hline
\end{tabular}

( $p>0.10,2$ d.f.)

Table 4: Cases requiring oral post op calcium admission.

Preloaded secondary hyperparathyroid cases

$5(100 \%)$

Non loaded secondary hyperparathyroid cases

$10(100 \%)$

Primary hyperparathyroid cases

$2(11.7 \%)$

New Transplants

2(66\%)

$(p<0.001,2$ d..f. $)$

\section{Discussion}

The average calcium levels on admission were highest for nonpreloaded cases, which may be explained by the fact that they did not require calcium supplementation, yet were lowest for preloaded cases, indicating they require more supplementation. Centrally placed are the primary cases, and new transplant cases, which demonstrate a lesser severe hypocalcaemia. As these results are significantly different, they could not have occurred due to chance. However, looking at the average calcium levels post op, the lowest level is demonstrated by the non-loaded cases, indicating preloading may have prevented a drop in calcium levels. This is followed by the level of the preloaded cases, and primary cases, and new transplant patients maintaining the highest average post op calcium level. However, these results are not significantly different and therefore could have occurred due to chance supplementation, yet only 2 cases each. The differences between the numbers of cases in each category requiring post op calcium supplementation are significant, with $100 \%$ of both preloaded and non-loaded secondary cases requiring oral supplementation, $11.6 \%$ primary hyperparathyroidism and $66 \%$ of new transplant cases requiring any supplementation, indicating a less severe post op hypocalcaemia. Although the doses of drugs given for each category were not significantly different, the actual numbers involved were. For preloaded cases, $100 \%$ required alfacalcidol, $80 \%$ were given calcichew, $40 \%$ calcium acetate and $20 \%$ calcium sandos. $90 \%$ required alfacalcidol, $60 \%$ calcichew, $40 \%$ calcium acetate and $30 \%$ calcium sandos. With non-loaded cases, although a lower percentage required each drug, higher doses were used compared to preloaded cases.

A good reflection of the usefulness of preloading is shown by the fact that none of the preloaded cases needed IVcalcium gluconate (Table 6), whereas 3 non-preloaded cases did require calcium supplementation, with very high average dose requirements of $16.1 \mathrm{mmol}$, compared to 2 cases, each primary and new transplant cases, with far lower dose requirements of $2.2 \mathrm{mmol}$ on average, again demonstrating a less severe post op hypocalcaemia (borderline significance).

It is also interesting to note how the more severe hypocalcaemia 
Table 5: Table showing type, doses and number in each category on each calcium supplementation.

\begin{tabular}{|c|c|c|c|c|c|c|c|c|c|c|}
\hline Av. dose/day & Alfacalcidol & $\begin{array}{l}\text { No. on } \\
\text { drug }\end{array}$ & Calcichew & $\begin{array}{l}\text { No. on } \\
\text { drug }\end{array}$ & $\begin{array}{l}\text { Calcium } \\
\text { acetate }\end{array}$ & $\begin{array}{l}\text { No on } \\
\text { drug }\end{array}$ & $\begin{array}{l}\text { Calcium } \\
\text { sandos }\end{array}$ & $\begin{array}{l}\text { No on. } \\
\text { drug }\end{array}$ & $\begin{array}{c}\text { Sando } \\
\text { cal }\end{array}$ & No. on drug \\
\hline Preloaded secondary & $2.82 \mathrm{mcg}$ & $\begin{array}{c}5 \\
100 \%\end{array}$ & 4.65 tabs & $480 \%$ & $\begin{array}{l}5.54 \\
\text { tabs }\end{array}$ & $\begin{array}{c}2 \\
40 \%\end{array}$ & $11.2 \mathrm{mls}$ & $\begin{array}{c}1 \\
20 \%\end{array}$ & - & 0 \\
\hline Primary cases & - & 0 & 1 tab & $\begin{array}{c}1 \\
6 \%\end{array}$ & - & 0 & - & 0 & - & 0 \\
\hline New transplants & $\begin{array}{l}1.83 \\
\mathrm{mcg}\end{array}$ & $\begin{array}{c}3 \\
100 \%\end{array}$ & - & 0 & - & 0 & - & 0 & - & 0 \\
\hline
\end{tabular}

Table 6: Number of cases in each category requiring IV calcium gluconate, and average dose.

\begin{tabular}{|l|l|l|}
\hline Preloaded secondary hyperparathyroid & 0 & - \\
\hline Non loaded secondary hyperparathyroid & 3 & $16.1 \mathrm{mmol}$ \\
\hline Primary hyperparathyroid & 1 & $2.2 \mathrm{mmol}$ \\
\hline New Transplants & 1 & $2.2 \mathrm{mmol}$ \\
\hline $\mathrm{P}>0.10,<0.05$ & & \\
\hline
\end{tabular}

Table 7: Average time (days) of hospital admission.

\begin{tabular}{|l|l|}
\hline Preloaded secondary hyperparathyroid cases & 6 \\
\hline Non loaded secondary hyperparathyroid cases & 7.5 \\
\hline Primary hyperparathyroid cases & 5.5 \\
\hline New Transplants & 4.3 \\
\hline$(p<0.001,2$ d.f.) & \\
\hline
\end{tabular}

may contribute to a prolonged hospital stay, (significantly different) with non-preloaded cases having the longest hospital stay at 7.5 days, followed by preloaded cases at 6 days, ending with primary and new transplant cases at 5.5 and 4.3 days respectively (Table 7).

The significance of this data is that we have demonstrated that preloading can effect pre post op calcium levels, as well as impact on usage of oral calcium supplementation, IV calcium replacement and length of hospital stay. As this audit was conducted at QEH, these results are generisable to that region.

Project limitation includes the fact we surveyed parathyroidectomies only over the period of 1 year, so larger numbers may make the results more reliable and give us differing results due to sample variability. We are also assuming all the data recorded on the computer system is correct.

\section{Conclusions}

All secondary hyperparathyroid cases admitted for parathyroidectomy should be preloaded with $4 \mathrm{mcg}$ alfacalcidol to prevent post op hypocalcaemia and IV calcium gluconate usage. Prior data from a preclerking audit indicates very few parathyroid cases are getting pre-screening appointments, so if we initiate this we can properly preload patients with $4 \mathrm{mcg}$ alfacalcidol. Both these should hopefully reduce the length of hospital stay and the risk of hypocalcaemia post op. We determined an association between preloading with alfacalcidol and increased risk of post op hypocalcaemia, IV calcium gluconate usage and prolonged hospital stay. Hopefully fewer cases of hypocalcaemia will be encountered post operatively, reducing patients length of hospital stay.

\section{References}

1. Alejandro VS, Nelson WJ, Huie P, Sibley RK, Dafoe D et al. (1995) Postischemic injury, delayed function and $\mathrm{Na}+-\mathrm{K}+-\mathrm{ATP}$ ase distribution in the transplanted kidney. Kidney Int 48: 1308-1315.

2. W Johnson, DR Taves, J Jowsey (1979) Fluoridation and bone disease in renal patients. In: E Johansen, DR Taves, TO Olsen, Eds. Continuing Evaluation of the Use of Fluorides. AAAS Selected Symposium. Westview Press, Boulder, Colorado 275-293

3. Potts JT, Jnr, (2002) Diseases of the parathyroid and otherhyper and hypocalcaemic disorders, from Harrison TR., Braunwald E., Harrisons' Principles of internal medicine. 15th ed. New York: McGraw-Hill 8-22.

4. Taniegra ED (2004) Hyperparathyrpoidism. American Family Physician 69: 333-339.

Copyright: (c) 2016 Goonewardene SS, et al. This is an open-access article distributed under the terms of the Creative Commons Attribution License, which permits unrestricted use, distribution, and reproduction in any medium, provided the original author and source are credited. 